\title{
Produção e qualidade do morangueiro em sistemas fechados de cultivo sem solo com emprego de substratos
}

\author{
Fruit production and quality of strawberry plants grown in closed soilless growing systems with \\ substrates
}

\author{
Rodrigo dos Santos Godoi ${ }^{\mathrm{I}}$ Jerônimo Luiz Andriolo ${ }^{\mathrm{I}^{*}}$ Gustavo Gimenez Franquéz $^{\mathrm{I}}$ \\ Djeimi Isabel Jänisch ${ }^{\mathrm{I}}$ Francieli Lima Cardoso $^{\mathrm{I}}$ Marcos André Braz Vaz ${ }^{\mathrm{I}}$
}

\section{RESUMO}

O objetivo do trabalho foi determinar o crescimento, a produção e a qualidade das frutas do morangueiro cultivado em três sistemas fechados sem solo e com dois substratos. Os sistemas foram testados no interior de um abrigo telado, no Departamento de Fitotecnia da UFSM, no período entre 27 de abril e 21 de novembro de 2006. Esses sistemas foram constituídos por sacolas fertirrigadas por tubos gotejadores e calhas e leito de cultivo fertirrigados por subirrigação. Foram empregados substrato orgânico Plantmax $P X T^{\circledR}$ e areia. $O$ delineamento experimental utilizado foi um fatorial $3 \times 2$, com quatro repetições. A fertirrigação foi feita com solução nutritiva completa, sem nenhum descarte durante todo o período experimental, e as frutas foram colhidas maduras. Foram determinados os seguintes parâmetros: a produção, a firmeza, a acidez e o teor de sólidos solúveis totais. Interações significativas entre os sistemas e os substratos foram observadas. Na areia, destacou-se o cultivo nas calhas, com produção de $1017,4 \mathrm{~g}$ planta $^{-1}$, sendo $8,13 \%$ e 8,33\% superior às sacolas e ao leito de cultivo, respectivamente. A produção mais elevada foi de $1196,5 \mathrm{~g}$ planta $^{-1}$, obtida com substrato orgânico no leito de cultivo, superior às sacolas em $10,9 \%$ e às calhas em 29,33\%. Concluiu-se que o cultivo sem solo do morangueiro sem descartes de solução nutritiva é possível e que a produção é influenciada pelo sistema de cultivo e pelo substrato, sem efeitos sobre a qualidade das frutas.

Palavras-chave: Fragaria $x$ ananassa, hidroponia, solução nutritiva, fertirrigação.

\section{ABSTRACT}

The objective of the research was to determine fruit production and quality of strawberry plants grown in three different closed soilless systems and two substrates. The experiment was conducted in a screenhouse at Department of
Fitotecnia, UFSM, from April to November, 2006. The soilless growing systems were plastic bags, plastic troughs and growing beds, and the substrates were sand and the organic substrate Plantmax $P X T^{\circledR}$. A $3 \times 2$ factorial experimental design was used, with four replications. Drip fertigation was used in the plastic bags and sub-irrigation in the other two systems. A standard complete nutrient solution was used without any disposal of it during the experiment. Ripe fruits were harvested and production, firmness, acidity and soluble solids were determined. A significant interaction among substrates and systems was observed. In sand, a mean fruit production of 1017,4 plants $^{-1}$ was obtained in plastic troughs, which was $8.13 \%$ e $8.33 \%$ higher than in plastic bags and growing beds, respectively. In the organic substrate, the higher fruit production was 1196,5 plants $^{-1}$ in growing beds. It was $10.9 \%$ and $29.33 \%$ higher than that in plastic bags and plastic troughs, respectively. It was concluded that strawberry soilless production might be done without any disposal of nutrient solution during the cropping period. Fruit production was affected by both the growing system and the substrate, without any effect on fruit quality.

Key words: Fragaria $x$ ananassa, hydroponics, nutrient solution, fertigation.

\section{INTRODUÇÃo}

O cultivo do morangueiro no solo enfrenta atualmente duas grandes limitações. A primeira diz respeito à incidência de moléstias, especialmente quando a lavoura é implantada no mesmo local por vários anos consecutivos. Esse fato está relacionado com o emprego de mudas de baixa qualidade sanitária,

IDepartamento de Fitotecnia, Universidade Federal de Santa Maria (UFSM), 97105-900, Santa Maria, RS, Brasil. E-mail: andriolo@smail.ufsm.br. *Autor para correspondência. 
sendo agravado pelos teores elevados de umidade no solo e nas folhas, além de umidade relativa do ar acima de $70 \%$, o que é freqüente no inverno e na primavera na região Sul do Brasil. O método tradicional que tem sido empregado para reduzir a incidência das moléstias dessa cultura é a desinfestação do solo com produtos químicos fumigantes. Entretanto, o emprego desse método enfrenta atualmente restrições de ordem ambiental (LIETEN, 1998; PARANJPE et al. 2003). A segunda limitação refere-se às dificuldades ergonômicas em cultivar as plantas na superfície do solo, as quais vêm dificultando o recrutamento de mãode-obra. O cultivo sem solo constitui uma alternativa para a superação desses problemas, por apresentar bancadas acima do nível do solo, facilitar o trabalho e reduzir a incidência de doenças radiculares. Esse sistema de cultivo já está difundido na Europa, principalmente na Inglaterra, Bélgica e Holanda (LIETEN et al., 2004). Para o cultivo do morangueiro, predominam os sistemas abertos, com plantas cultivadas em sacolas ou vasos contendo diferentes tipos de substratos com drenagem perdida de solução nutritiva. No Brasil, foram encontrados resultados de pesquisas sobre o cultivo do morangueiro em sistemas hidropônicos do tipo NFT (FERNANDES JÚNIOR et al., 2002; BONNECARRÈRE, 2002; VILLELA JÚNIOR et al., 2004) ou com substrato em colunas verticais (FERNANDES JÚNIOR et al., 2002). A produtividade máxima nesses sistemas situou-se próxima a 400 glanta $^{-1}$. Os sistemas do tipo Nutrient Film Technique (NFT) caracterizam-se por renovações freqüentes da solução nutritiva, elevado consumo de energia elétrica para o funcionamento de bombas e baixa inércia térmica. As colunas verticais com substrato exigem estruturas reforçadas de sustentação, são de instalação laboriosa e funcionam em sistema aberto, com descarte da solução nutritiva drenada (FURLANI \& FERNANDES JÚNIOR, 2004). Não foram encontrados na literatura resultados de pesquisas com sistemas fechados e emprego de substratos, com baixo consumo de energia elétrica e descarte reduzido da solução nutritiva.

O objetivo do trabalho foi determinar o crescimento, a produção e a qualidade das frutas do morangueiro em três sistemas fechados sem solo e com dois substratos.

\section{MATERIAL E MÉTODOS}

O experimento foi conduzido no interior de um abrigo de $200 \mathrm{~m}^{2}$, coberto com polietileno de baixa densidade de $150 \mu \mathrm{m}$ de espessura e com paredes revestidas de tela antiinsetos com malha de $1,5 \times 10^{-3} \mathrm{~m}$, localizado no Departamento de Fitotecnia da Universidade Federal de Santa Maria, Rio Grande do Sul (RS). Para o leito de cultivo e as sacolas, as unidades experimentais foram formadas por telhas de fibrocimento com $3,60 \mathrm{~m}$ de comprimento, $1,10 \mathrm{~m}$ de largura, canais de $0,06 \mathrm{~m}$ de altura e $0,18 \mathrm{~m}$ de distância entre canais, apoiadas sobre suportes de madeira a $0,80 \mathrm{~m}$ de altura do solo, com declividade de $1 \%$. A superfície das telhas foi revestida com filme transparente de polietileno de baixa densidade com espessura de $100 \mu \mathrm{m}$. Os canais foram preenchidos com brita basáltica média empregada na construção civil, com tamanho de partículas entre 0,015m e 0,020m. Para as calhas foi construído um suporte de madeira a $0,80 \mathrm{~m}$ de altura, sobre o qual foi colocada uma base. Essa base, também de madeira, tinha dimensões de: 0,20m, 0,025m e 3,60m de largura, espessura e comprimento, respectivamente. A largura total da unidade experimental foi de $1,10 \mathrm{~m}$ e o comprimento foi de $3,60 \mathrm{~m}$, com declividade de 1\%. Um reservatório de material anticorrosivo com capacidade para 500L foi instalado próximo à extremidade inferior das telhas para armazenar a solução nutritiva (ANDRIOLO, 2007).

Os tratamentos foram constituídos por três sistemas de cultivo (Figura 1) e dois substratos, em um fatorial 3 x 2 no delineamento inteiramente casualizado, com quatro repetições. Cada parcela foi constituída por uma unidade do dispositivo experimental com 48 plantas por parcela. Foram consideradas bordaduras as plantas em cada uma das fileiras laterais e nas extremidades de cada fileira.

As sacolas de polietileno contendo $4 \mathrm{dm}^{3}$ de substrato foram distribuídas em quatro fileiras distantes $0,30 \mathrm{~m}$ entre si e $0,26 \mathrm{~m}$ entre fileiras, comportando uma planta por sacola. Essas sacolas foram colocadas sobre a camada de brita e perfuradas na parte inferior. A solução nutritiva foi fornecida às plantas por meio de uma motobomba $(0,27-0,55 \mathrm{KW}$, vazão de $2.100 \mathrm{~L} \mathrm{~min}^{-1}$ ) conectada ao reservatório de estocagem da solução nutritiva e a tubos gotejadores com vazão unitária de $1,4 \mathrm{~L} \mathrm{~h}^{-1}$, com um gotejador por sacola. Em cada fertirrigação, a solução nutritiva excedente à capacidade máxima de retenção do substrato foi drenada, passando pelas perfurações localizadas na base da sacola e, em seguida, através da camada de brita, retornando ao reservatório de estocagem.

As calhas foram construídas sobre uma base de madeira, em forma de U, com largura de $0,18 \mathrm{~m}$ e altura de $0,12 \mathrm{~m}$, empregando filme de polietileno de baixa densidade de $150 \mu \mathrm{m}$, fixado na parte superior em um fio de arame galvanizado número 15 . A camada de brita e a tela de polietileno de malha $1,5 \times 10^{-3} \mathrm{~m}$ foram 


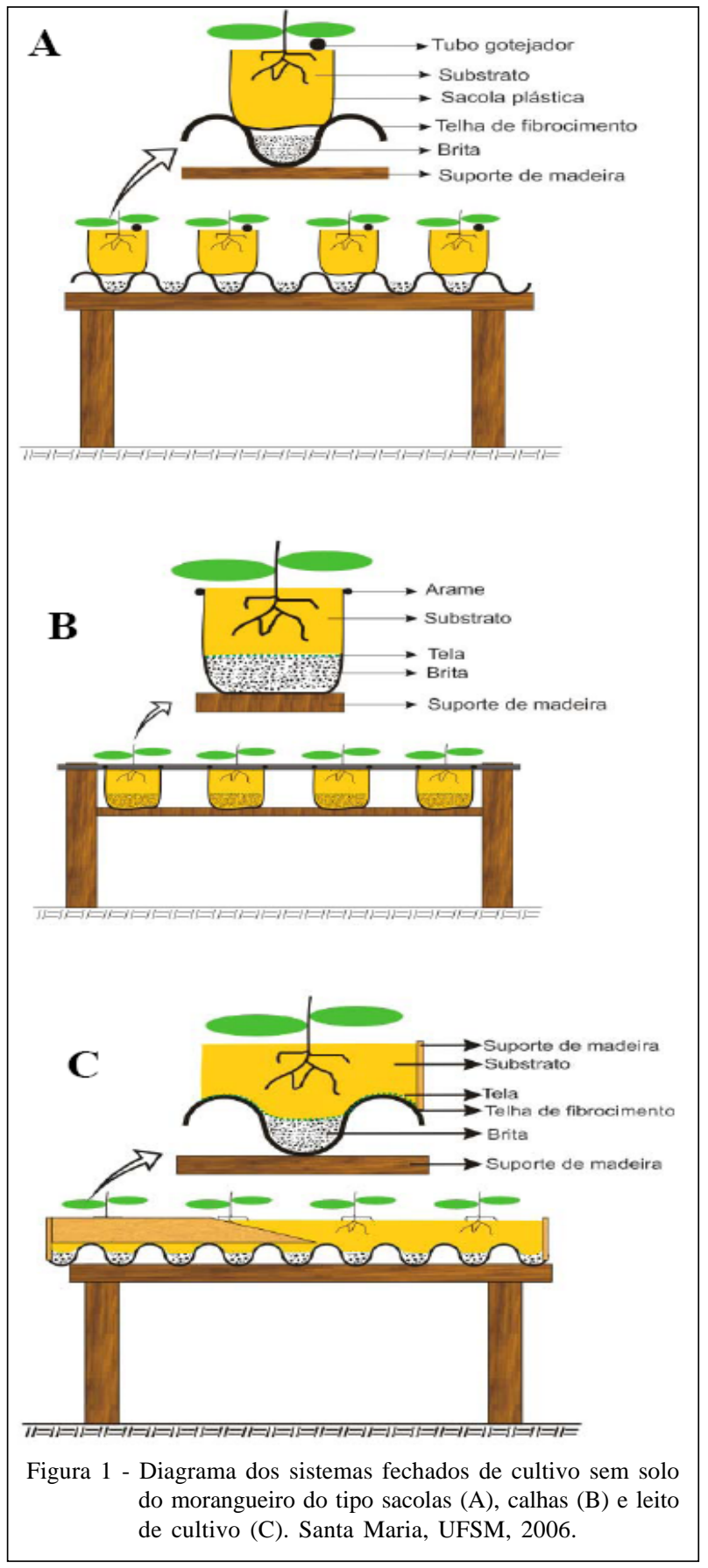

colocadas no interior da calha. A distância entre as calhas foi de $0,26 \mathrm{~m}$, as quais foram preenchidas com uma camada de substrato de $0,09 \mathrm{~m}$. A solução nutritiva foi fornecida na extremidade mais alta da calha através de uma mangueira flexível conectada a uma bomba submersa no interior do reservatório (bomba de aquário, 8W, vazão de 520 $\mathrm{L} \mathrm{h}^{-1}$ ) e a um tubo de PVC de 0,025m de diâmetro e $1,0 \mathrm{~m}$ de comprimento, perfurado a cada $0,0025 \mathrm{~m}$. A solução nutritiva fluiu através da brita difundindo-se na camada de substrato, caracterizando a fertirrigação pelo método da subirrigação. $\mathrm{O}$ volume excedente à capacidade máxima de retenção do substrato retornava ao reservatório.

O leito de cultivo foi formado sobre toda a superfície da telha, preparada conforme descrição para o sistema de sacolas. Uma tela antiinsetos com malha de $1,5 \times 10^{-3} \mathrm{~m}$ foi colocada sobre a brita para suportar uma camada de substrato com $0,09 \mathrm{~m}$ de altura. A solução nutritiva foi conduzida do reservatório de estocagem até a extremidade mais alta da telha da mesma forma como nas calhas. Essa solução foi distribuída transversalmente no leito de cultivo através de um tubo de PVC de 0,025m de diâmetro e 1,0m de comprimento, com perfurações de $0,0025 \mathrm{~m}$ feitas ao longo do tubo. A fertirrigação e a drenagem da solução nutritiva ocorreram de modo semelhante ao processo descrito nas calhas.

Em cada sistema de cultivo, a superfície dos substratos foi revestida com filme de polietileno de coloração preta a fim de evitar a incidência dos raios solares. A densidade de plantas empregada foi de 12,12 plantas $\mathrm{m}^{-2}$. O volume de substrato disponível para cada planta foi de $4 \mathrm{dm}^{3}$ nas sacolas e calhas e de $7,5 \mathrm{dm}^{3}$ no leito de cultivo.

Foram empregados dois substratos, a areia na categoria inerte e o Plantmax $\mathrm{PXT}^{\circledR}$ na categoria orgânica. As características físicas da areia e do substrato orgânico foram determinadas no Laboratório de Física do Solo da UFSM. A densidade aparente foi de 1.608,6 e 405,6g dm $\mathrm{gm}^{-3}$ e a capacidade de retenção de água foi de 198,6 e $466,5 \mathrm{~mL} \mathrm{dm}^{-3}$, respectivamente. A granulometria da areia foi determinada em seis classes com diâmetros de $2 ; 1 ; 0,5 ; 0,25$ e $0,106 \times 10^{-3} \mathrm{~m}$, sendo a última com tamanho de partículas inferior a menor peneira. A análise química do substrato orgânico foi realizada no Laboratório de Análise de Solos da UFSM, indicando quantidades de 14,3 e $5,6 \mathrm{cmol} \mathrm{dm}^{-3}$ de Ca e Mg, respectivamente; 128,1, 76,0 e 600 $\mathrm{mg} \mathrm{dm}^{-3}$ para S, P e K, respectivamente; $16,6 \%$ de matéria orgânica e pH igual a 5,1.

A formulação da solução nutritiva foi calculada com base na proposta de FURLANI \& FERNANDES JÚNIOR (2004), modificada para atingir relações iônicas $\mathrm{NO}_{3}{ }^{-} / \mathrm{K}^{+}$de $1,4 \mathrm{e} \mathrm{K}^{+} /\left(\mathrm{Ca}^{2+}+\mathrm{Mg}^{2+}\right)$ de 1,1 e somatório iônico de $14,2 \mathrm{meq} \mathrm{L}^{-1}$. As concentrações em mmol L-1 foram de: 10,2 de $\mathrm{NO}_{3}^{-} ; 2 \mathrm{de}_{2} \mathrm{PO}_{4}^{-} ; 7,4$ de $\mathrm{K}^{+} ; 2,4 \mathrm{de} \mathrm{Ca}^{++} ; 1$ de $\mathrm{Mg}^{++}$e 1 de $\mathrm{SO}_{4}^{--}$. A condutividade elétrica foi de $1,6 \mathrm{dS} \mathrm{m}^{-1}$ e o $\mathrm{pH}$ foi de 5,7 . Os micronutrientes foram fornecidos em $\mathrm{mg} \mathrm{L}^{-1}$ nas concentrações de: 0,03 de Mo; 0,42 de B; 0,06 de Cu; 
0,50 de Mn; 0,22 de Zn e 1,0 de Fe. As fontes de fertilizantes empregados foram o nitrato de potássio $\left(\mathrm{KNO}_{3}\right)$, nitrato de cálcio $\left[\left(\mathrm{CaNO}_{3}\right)_{2}\right]$ (Calcinit), monofosfato de potássio $\left(\mathrm{KH}_{2} \mathrm{PO}_{4}\right)$ e sulfato de magnésio $\left(\mathrm{MgSO}_{4}\right)$. O manejo da composição da solução nutritiva e da fertirrigação foi feito de acordo com as indicações de MORAES \& FURLANI (1999). Para tal, foram programadas três fertirrigações diárias de 15 minutos no substrato Plantmax e quatro na areia, às $9 \mathrm{~h}, 13 \mathrm{~h}$ e $16 \mathrm{~h} 30 \mathrm{~min}$ e às $9 \mathrm{~h}, 11 \mathrm{~h}, 13 \mathrm{~h}$ e $16 \mathrm{~h} 30 \mathrm{~min}$, respectivamente. Foi mantida a mesma freqüência de fertirrigações nos três sistemas de cultivo para cada tipo de substrato e nenhum descarte de solução nutritiva foi feito até o final do experimento.

O plantio foi realizado no dia 27 de abril e o experimento foi encerrado em 21 de novembro de 2006, com a cultivar Arazá, de origem uruguaia. A condução e o manejo foram feitos de acordo com as indicações técnicas para a cultura (ANTUNES \& DUARTE FILHO, 2003). Para a determinação da produtividade (P), foi utilizada a seguinte fórmula: $\mathrm{P}=\mathrm{mff}\left(\mathrm{kg}_{\mathrm{planta}}{ }^{-1}\right) \mathrm{x}$ densidade (plantas $\mathrm{m}^{-2}$ ) $\mathrm{x}$ área de um ha( $\left(\mathrm{em} \mathrm{m}^{2}\right.$ ), sendo $m f f$ a massa fresca de frutas. As colheitas foram feitas duas vezes por semana na área útil de cada parcela, na fase de maturação completa, correspondente ao estádio fenológico 87 (HENNION \& VESCHAMBRE, 1997). No final do experimento, as colheitas foram somadas para obter a produção total. Para obtenção dos parâmetros de qualidade, as frutas foram conduzidas ao laboratório de Pós-Colheita da UFSM para determinação da firmeza com penetrômetro de ponteira de $8 \mathrm{~mm}$, acidez titulável e teor de sólidos solúveis totais por refratometria (AOAC, 1990). Para determinação do crescimento, quatro plantas foram identificadas aleatoriamente logo após o plantio, em cada parcela. A massa seca das frutas colhidas dessas plantas durante o período do experimento foi determinada após secagem em estufa de circulação forçada de ar $\left(65^{\circ} \mathrm{C}\right)$. A massa seca de frutas de cada colheita foi somada ao final do experimento para obter a massa seca total de frutas de cada planta. Ao final do experimento, essas plantas foram coletadas, e a massa seca da parte aérea foi determinada. Os resultados foram submetidos à análise de variância pelo teste $F$ e a significância entre as diferenças de mais de duas médias foi testada pelo teste de Tukey a 5\% de probabilidade de erro.

\section{RESULTADOS E DISCUSSÃO}

As variações medidas na CE situaram-se entre 1,4 e $1,8 \mathrm{dS} \mathrm{m}^{-1}$, com média de $1,7 \mathrm{dS} \mathrm{m} \mathrm{m}^{-1}$ durante todo o período de condução da cultura. As variações de pH situaram-se entre 5,0 e 6,4, com média de 5,6 no mesmo período.

Houve interação significativa entre os sistemas e os substratos para produção precoce e total (Tabela 1). Na areia, a produção precoce foi similar nas sacolas e nas calhas, enquanto no substrato orgânico foi similar nas sacolas e no leito de cultivo. A produção total foi mais elevada nas calhas quando o substrato foi a areia e no leito de cultivo quando o substrato foi orgânico.

O maior crescimento das plantas também foi atingido no substrato orgânico (Tabela 2). Na areia, a massa seca total mais elevada foi constatada nas sacolas e atribuída ao maior crescimento vegetativo das plantas. Nesse substrato, a maior produção ocorreu nas calhas, onde houve menor crescimento vegetativo das plantas. A menor produção foi observada no leito de cultivo, onde o crescimento vegetativo foi $47,2 \%$ superior àquele das calhas.

O maior crescimento total da planta ocorrido no leito de cultivo com substrato orgânico é atribuído ao crescimento mais elevado tanto da massa da parte aérea, quanto das frutas. Esse resultado pode ser explicado pelo maior crescimento radicular em função

Tabela 1 - Produção precoce e total do morangueiro, em g planta ${ }^{-1}$, nos três sistemas fechados de cultivo sem solo e dois substratos. Santa Maria, UFSM, 2006.

\begin{tabular}{|c|c|c|c|c|}
\hline \multirow[b]{2}{*}{ Sistemas } & \multicolumn{2}{|c|}{ 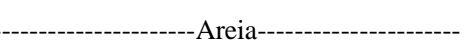 } & \multicolumn{2}{|c|}{----'Plantmax PXT } \\
\hline & Precoce & Total & Precoce & Total \\
\hline Sacolas & $434,1 \mathrm{AB} \mathrm{b}^{\mathrm{I}}$ & $934,7 \mathrm{Ba}$ & $643,7 \mathrm{Aa}$ & $1065,2 \mathrm{~B} \mathrm{a}$ \\
\hline Leito & 355,3 B b & $932,7 \quad \mathrm{C} \mathrm{b}$ & $586,8 \mathrm{~A}$ a & $1196,5 \mathrm{~A} \mathrm{a}$ \\
\hline Calhas & $450,1 \mathrm{Aa}$ & $1017,4 \mathrm{Aa}$ & 321,6 B b & $845,5 \mathrm{C} \mathrm{b}$ \\
\hline Média & 413,2 & 961,6 & 517,4 & 1035,7 \\
\hline Cv (\%) & 12,4 & 5,0 & 12,4 & 5,0 \\
\hline
\end{tabular}

${ }^{\text {I }}$ Médias seguidas por letras maiúsculas distintas na coluna e minúsculas na linha diferem entre si pelo teste de Tukey a 5\% de probabilidade.

Ciência Rural, v.39, n.4, jul, 2009. 
Tabela 2 - Massa seca vegetativa (MSV), massa seca das frutas (MSF) e massa seca total (MST) do morangueiro em função de três sistemas fechados de cultivo sem solo e dois substratos. Santa Maria, UFSM, 2006.

\begin{tabular}{|c|c|c|c|c|c|c|}
\hline \multirow{3}{*}{ Sistemas } & \multicolumn{3}{|c|}{ 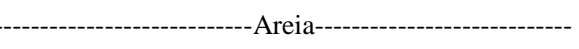 } & \multicolumn{3}{|c|}{ 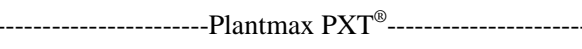 } \\
\hline & MSV & MSF & MST & MSV & MSF & MST \\
\hline & \multicolumn{6}{|c|}{ g planta ${ }^{-1}$} \\
\hline Sacolas & $41,2 \mathrm{~A} \mathrm{a}$ & $28,0 \mathrm{Ba}$ & $69,2 \mathrm{~A} \mathrm{a}$ & $38,0 \mathrm{~B} \mathrm{~b}$ & $29,8 \mathrm{Ba}$ & $67,8 \mathrm{Ba}$ \\
\hline Leito & $37,1 \mathrm{~B} \quad \mathrm{~b}$ & $24,5 \mathrm{C} \mathrm{b}$ & $61,6 \mathrm{~B} \quad \mathrm{~b}$ & $43,5 \mathrm{~A} \mathrm{a}$ & $33,4 \mathrm{Aa}$ & $76,9 \mathrm{~A} \mathrm{a}$ \\
\hline Calhas & $25,2 \mathrm{Ca}$ & $32,9 \mathrm{~A} \mathrm{a}$ & $58,1 \mathrm{Ca}$ & $26,6 \mathrm{Ca}$ & $22,6 \mathrm{Cb}$ & $49,2 \mathrm{Cb}$ \\
\hline Média & 34,5 & 28,5 & 63,0 & 36,0 & 28,6 & 64,6 \\
\hline Cv (\%) & 4,4 & 5,0 & 2,5 & 4,4 & 5,0 & 2,5 \\
\hline
\end{tabular}

${ }^{\mathrm{I}}$ Médias seguidas por letras maiúsculas distintas na coluna e minúsculas na linha diferem entre si pelo teste de Tukey a 5\% de probabilidade.

do maior volume de substrato empregado, o que possibilitaria maior disponibilidade de água e nutrientes essenciais para o crescimento e desenvolvimento das plantas. A menor produção que ocorreu nas calhas com substrato orgânico foi acompanhada também por um crescimento reduzido da massa da parte aérea (Tabela 2). Não foram observadas diferenças significativas nas variáveis de qualidade das frutas entre os sistemas de cultivo e os substratos. Os valores médios foram de 5,9N para a firmeza de polpa, $6,4^{\circ}$ Brix para os sólidos solúveis totais e $11,1 \mathrm{meq} 100 \mathrm{~mL}^{-1}$ para a acidez.

A produção média atingida neste experimento foi de 998,7g planta $^{-1}$. Essa quantidade foi 4,3 e 2,7 vezes superior àquelas obtidas por FERNANDES JÚNIOR et al. (2002) em colunas verticais e em NFT, as quais foram de 233,2 e 364,4g planta ${ }^{-1}$, respectivamente. A quantidade foi também 31\% superior àquela obtida nas lavouras de alta tecnologia no Rio Grande do Sul (MADAIL et al., 2005). Embora a produção do morangueiro seja influenciada pelas condições ambientais, determinantes do período de floração e frutificação da cultura, as diferenças encontradas entre os sistemas testados neste trabalho e aqueles de outros autores podem ter sido influenciadas tanto pelo arranjo das plantas, quanto pela eficiência da fertirrigação. Os sistemas deste trabalho simulam canteiros em bancadas formando uma cobertura vegetal homogênea em um único nível. Esse arranjo é provavelmente mais eficiente na interceptação da radiação solar do que aquele em colunas verticais. Além disso, a disposição dos substratos na forma de leito de cultivo e das calhas fertirrigadas por subirrigação pode ter favorecido a uniformidade de molhamento dos substratos, disponibilizando maior volume de solução nutritiva para cada planta.

Os resultados indicam que, no caso de ser empregada a areia, as calhas devem ser preferidas. Ao ser empregado o substrato orgânico, o leito de cultivo é o sistema mais produtivo. Essas diferenças entre os substratos são atribuídas às características físicas dos materiais. A capacidade de retenção de água da areia sendo 2,3 vezes inferior àquela do substrato orgânico Plantmax $\mathrm{PXT}^{\circledR}$ implica maiores variações na disponibilidade de água às plantas entre as fertirrigações diárias. Essas variações seriam ainda maiores nas sacolas, onde a fertirrigação é feita através de um único gotejador por planta. Nesse método de fertirrigação pode ocorrer distribuição desuniforme da solução nutritiva no interior do substrato, como observado por MAROUELLI et al. (2005) em bags empregados no cultivo do tomateiro em substrato. Restrições na disponibilidade hídrica retardariam o crescimento inicial da planta, com atraso na frutificação, explicando a menor produção obtida nas sacolas em relação às calhas. Esse resultado indica que a freqüência e a duração das fertirrigações devem ser ajustadas de acordo com as características físicas de cada substrato e com o método de fertirrigação empregado.

A tabela 2 mostra que a maior produção de frutas não vem sempre associada ao crescimento vigoroso da parte vegetativa da planta. Esse resultado indica a necessidade de realizar pesquisas para ajustar relações capazes de indicar critérios de manejo do crescimento desses dois compartimentos da planta. $\mathrm{O}$ menor crescimento vegetativo, principalmente da área foliar, pode ser vantajoso porque essa variável afeta o consumo de solução nutritiva. A coloração e a qualidade das frutas também são características que podem ser beneficiadas em plantas com menor superfície de folhas e maior exposição à radiação solar.

Os sistemas fechados de cultivo sem solo permitem atingir níveis elevados de produção, acrescentando inovações que lhes conferem vantagens em relação àqueles que vêm sendo empregados atualmente na cultura do morangueiro, como, por exemplo, não haver descarte da solução nutritiva 
durante todo período de produção. Fato esse que diminui os custos com fertilizantes, uma vez que não há lixiviação de nutrientes e nem substituição de solução nutritiva. O consumo de energia elétrica é menor, especialmente nos sistemas de calhas e no leito de cultivo, nos quais uma bomba de pequena potência é empregada. O número diário de fertirrigações é baixo, principalmente quando comparado ao regime intermitente de $15 \mathrm{~min}$ ou 30min empregado em sistemas do tipo NFT (MORAES \& FURLANI, 1999). O risco de disseminação de pragas e moléstias associadas ao uso prolongado de uma mesma solução nutritiva em sistema fechado é minimizado pelo emprego de unidades de produção independentes. Outra vantagem reside no fato de esses sistemas dispensarem a substituição dos substratos ao final de cada ciclo de produção. No caso do substrato inerte, a estabilidade física do material persiste ao longo dos anos. No caso de substratos orgânicos, a reposição de volumes complementares pode ser feita facilmente, sem descartar aqueles empregados anteriormente (FERNANDES, C. et al. 2006). Essas características permitem prever o emprego de outros materiais como substrato, de forma a adaptar o sistema de produção às peculiaridades de cada região de produção.

\section{CONCLUSÕES}

O crescimento e a produção do morangueiro são influenciados pelo sistema fechado de cultivo sem solo e pelo substrato. As maiores produções são obtidas com o emprego de areia no sistema de calhas e com o emprego de substrato orgânico no sistema constituído por um leito de cultivo e sacolas. A qualidade das frutas da cultivar Arazá não é influenciada pelos sistemas e substratos.

\section{AGRADECIMENTOS}

Ao Conselho Nacional de Desenvolvimento Científico e Tecnológico (CNPq), pelo auxílio financeiro, processo 470177/2006-3, pela bolsa de produtividade em Pesquisa a Jerônimo Luiz Andriolo e pela bolsa PIBIC-UFSM a Djeimi Isabel Jänisch. À Fundação de Amparo à Pesquisa do RS (FAPERGS), pela bolsa BIC para Francieli Lima Cardoso.

\section{REFERÊNCIAS}

ANDRIOLO, J.L. Preparo e manejo da solução nutritiva na produção de mudas e de frutas do morangueiro. In: SEMINÁRIO SOBRE O CULTIVO HIDRÔPONICO DE MORANGUEIRO, 2007, Santa Maria, RS. Anais... Santa Maria: UFSM, CCR, Departamento de Fitotecnia, 2007. 60p. p.41-50.

ANTUNES, L.E.C.; DUARTE F.J. Produção de mudas de morango. In: SANTOS, A.M. dos; MEDEIROS, A.R.M. (Ed.). Sistema de produção do morango. Sistemas de produção, 5.
Pelotas: EMBRAPA CT, 2003. Capturado em 5 mar. 2006. Online. Disponível em: <http;//www.cpact.embrapa/ sistema/ morango $>$.

ASSOCIATION OF OFFICIAL ANALYTICAL CHEMISTS. Official methods of analysis of the Association of Official Analytical Chemists. 15.ed. Arlington, 1990. 1298p.

BONNECARRÈRE, R.A.G. Soluções nutritivas e formas de manejo do morangueiro em hidroponia. 2002. $55 \mathrm{f}$. Dissertação (Mestrado em Agronomia) - Curso de Pós-graduação em Agronomia, Universidade Federal de Santa Maria.

FERNANDES, C. et al. Desempenho de substratos no cultivo do tomateiro do grupo cereja. Horticultura Brasileira, Brasília, v.24, n.1, p.42-46, 2006.

FERNANDES-JÚNIOR, F. et al. Produção de frutos e estolhos de morangueiro em diferentes sistemas de cultivo em ambiente protegido. Bragantia, Campinas v.61, n.1, p.25-34, 2002. Disponível em: http://www.scielo.br/scielo.php?script=sci_arttext\&pid=S000687052002000100005\&lng=en\&nrm=iso\&tlng=pt. Doi: 10.1590/ S0006-87052002000100005.

FURLANI, P.R.; FERNANDEZ JÚNIOR, F. Cultivo hidropônico de morango em ambiente protegido. In: SIMPÓSIO NACIONAL DO MORANGO \& ENCONTRO DE PEQUENAS FRUTAS E FRUTAS NATIVAS DO MERCOSUL, 2., 2004, Pelotas. Anais... Pelotas: Corrêa Antunez, L.E. et al. (Ed.). EMBRAPA, 2004. p.102-115. (Documentos 124).

HENNION, B.; VESCHAMBRE, D. La fraise: maîtrise de la production. Paris: CTIFL, 1997. 299p.

LIETEN, F. La fragola in Belgio-Olanda. In: LA FRAGOLA VERSO IL 2000. Convegno Nazionale. Verona: Camera di Commercio Industria Artigianato e Agricultura di, $1998 . \quad$ p.8394.

LIETEN, F. et al. Recent situation of strawberry substrate culture in Europe. Acta Horticulturae, Leuven, Belgium, v.649, p.193-196, 2004.

MADAIL, J.C.M. et al. Coeficientes técnicos para a cultura do morangueiro. In: SISTEMA DE PRODUÇÃO, 5., 2005, Pelotas Anais... Capturado em 24 mai. 2006. Online. Disponível na Internet: Online. Disponível na Internet. http:// sistemasdeproducao,cnptia.embrapa.br/FontesHTML/Morango/ SistemaProducaomorango.

MAROUELLI, W.A. et al. Variabilidade espacial do sistema radicular do tomateiro em implicações no manejo da irrigação em cultivo sem solo com substratos. Horticultura Brasileira, v.23, n.1, p.57-60, 2005.

MORAES, C.A.G.; FURLANI, P.R. Cultivo de hortaliças de fruto em hidroponia. Informe Agropecuário, Belo Horizonte, v.20, n.200/201, p.105-113. 1999.

PARANJPE A. et al. Winter strawberry production in greenhouses using soilless substrates: an alternative to methyl bromide soil fumigation. Horticultural Science. Proceedings Florida State v.116, p.98-105, 2003.

VILLELA JÚNIOR, L.V. et al. Análise do resfriamento da solução nutritiva para cultivo hidropônico do morangueiro. Engenharia Agrícola, Jaboticabal, v.24, n.2, p.338-346, 2004. 